\title{
De lo efímero a lo perdurable, el sello de la religión cristiana en el paisaje: el sistema constructivo de los edificios religiosos primitivos en la región de Acámbaro
}

From the Ephemeral to the Enduring, the Hallmark of the Christian Religion on the Landscape: the Construction System of Primitive Religious Buildings in the Acámbaro Region

\section{Karine Lefebvre*}

CENTRO DE INVESTIGACIONES EN GEOGRAFÍA AMBIENTAL, UNAM CAMPUS MORELIA, karine.lefebvre07@gmail.com

En el transcurso del siglo xvi, los distintos edificios religiosos de la región de Acámbaro presentan gran diversidad tanto de morfologías como de materiales de construcción. A partir de la confrontación de datos históricos y arqueológicos, este artículo analiza diferentes aspectos tipológicos y funcionales para comprender las relaciones que unen la naturaleza de los materiales de construcción con el papel de las estructuras en la jerarquía religiosa y su evolución en el tiempo.

Palabras Clave: conquista religiosa, sistema constructivo, edificios primitivos, recursos naturales, Michoacán.

In the course of the $16^{\text {th }}$ century, different religious buildings in the Acámbaro region presented a great diversity of morphologies and construction materials. Based on historical and archaeological data, this article analyzes different typological and functional aspects in order to better understand the relationships that linked the nature of the building materials used to the role of those structures in the religious hierarchy and their evolution over time.

KEYWORDS: religious conquest, construction systems, primitive buildings, natural resources, Michoacán.

Fecha de recepción: 12 de noviembre de 2015 / Fecha de aceptación: 17 de mayo de 2016 / Fecha de la versión definitiva: 17 de enero de 2017

a conquista española de la región de Acámbaro fue temprana por ser un punto estratégico, a la vez como acceso privilegiado hacia el corazón del reino tarasco (vía los valles que llevaban a Zinapécuaro y luego a Pátzcuaro), pero también como puerta de entrada hacia la comarca septentrional que llamarán la Gran

* Este artículo fue originalmente el objeto de una ponencia en el marco del "Primer coloquio mexicano de historia de la construcción: materiales, técnicas y mano de obra”, del 28 al 31 de octubre de 2014, Ciudad de México. 
Chichimeca. Esta región allende del río Grande fue particularmente codiciada por los españoles, en un primer tiempo por las amplias llanuras fértiles favorables al establecimiento unidades agropecuarias, pero, sobre todo, a partir de la mitad del siglo Xvi por el descubrimiento de minas de metal precioso, tal como Guanajuato y Zacatecas. Por lo tanto, las fundaciones españolas precoces de Acámbaro y de los pueblos vecinos fueron estrechamente relacionadas con las campañas militares llevadas a cabo en contra de los pueblos "hostiles" chichimecas. Este dominio temprano se acompañó de una reorganización general del patrón de asentamiento local. Los poblados indígenas ocupados en víspera de la Conquista, principalmente establecidos en lugares altos (cima de cerritos y pendientes altas), fueron sistemáticamente desplazados y transferidos hacia las planicies y los valles cercanos (generalmente en un perímetro reducido), ya que por su posición dominante podían representar un peligro para los colonos. Esta política general de reorganización territorial ocurrió muy poco tiempo después de la llegada de los españoles, de hecho con frecuencia se habla de una fase de congregaciones tempranas, que afectó no solamente a los asentamientos mayores, sino también a los pueblos sujetos.

La conquista espiritual del México antiguo siguió los pasos de los conquistadores. Ferviente católico, Hernán Cortes exigió desde 1524 el envío de misioneros con el fin de emprender la cristianización de los naturales. Se encargó a las órdenes mendicantes la responsabilidad de la misión de evangelización, en particular a los franciscanos, a los dominicanos y a los agustinos. La distribución de las provincias en el seno de estos grupos religiosos resultó de la cronología de su llegada respectiva a México y de su campo de acción. Así, la región de Acámbaro, que pertenece al obispo de Michoacán, se repartió de manera desigual entre los franciscanos y los agustinos. ${ }^{1}$ Los franciscanos fueron los primeros en establecerse. Aún an-

${ }^{1}$ Pertenece desde 1535 a la custodia franciscana de San Pedro y San Pablo de Michoacán y desde la segunda mitad del siglo xvı a la provincia agustina de México. A partir de 1602, esta última se escinde en dos, dando lugar a la provincia del Santísimo Nombre de Jesús, que tenía como centro a México, y la provincia de San Nicolás de Tolentino de Michoacán, de la cual depende la región de estudio. 
tes de 1530, fundaron los conventos de Zinapécuaro y de Acámbaro (Beaumont 1932, 156). La carencia numérica de misioneros no permitía multiplicar los conventos. Por consecuencia, no todas las cabeceras (centros administrativos coloniales) poseían conventos, el establecimiento de cada uno debía ser debidamente reflexionado. El convento de Acámbaro se asentó en una de las cabeceras, la más importante y más poblada de la zona. En Zinapécuaro, la implantación del convento debía favorecer la cristianización de uno de los principales polos religiosos del antiguo reino tarasco, puesto que este pueblo acogía el templo de la diosa Cueravapéri, madre de todos los dioses (Alcalá 2008, 12). De esta manera, los franciscanos centraron sus esfuerzos a lo largo del valle del Lerma y de la cuenca de Cuitzeo, es decir, en el sector bajo de la región, de acceso fácil. En cambio, en un primer tiempo, la zona montañosa de Ucareo quedó relativamente abandonada de la obra evangelizadora. Durante la primera mitad del siglo XVI, los pueblos de la sierra estuvieron bajo el cargo de religiosos franciscanos de Acámbaro, de Zinapécuaro e incluso de Taximaroa, que tomaban turno para dar los oficios divinos a las poblaciones. Pero en este amplio sector, la geografía accidentada volvía difícil el desplazamiento de los misionarios. Por consiguiente, 25 ańos después de la Conquista, todavía el cristianismo estaba poco arraigado entre la población. Aprovechando este espacio vacío, los agustinos se establecieron en la sierra y fundaron un convento en la cabecera Ucareo, para responder así a una verdadera necesidad evangelizadora.

A partir de estos tres conventos, la religión de los conquistadores se difundió a través de una amplia red de iglesias, capillas y hospitales, establecidos en los pueblos secundarios (figura 1). La cristianización de las poblaciones, proyecto de gran envergadura, se acompañó de una verdadera "fiebre constructiva", que marcó cada nivel de la sociedad con la huella del nuevo culto. Cada escalón de esta pirámide eclesiástica tenía su función. Los conventos, que alojaban a los misioneros, se convirtieron en polos religiosos mayores. A partir de ellos, los frailes radiaban en la provincia, viniendo a predicar por turno desde este punto hacia las iglesias construidas en los pueblos secundarios que sólo acogían los divinos oficios. 
Figura I. Síntesis del patrón de asentamientos religiosos en la región de Acámbaro durante el siglo Xvi según las fuentes históricas

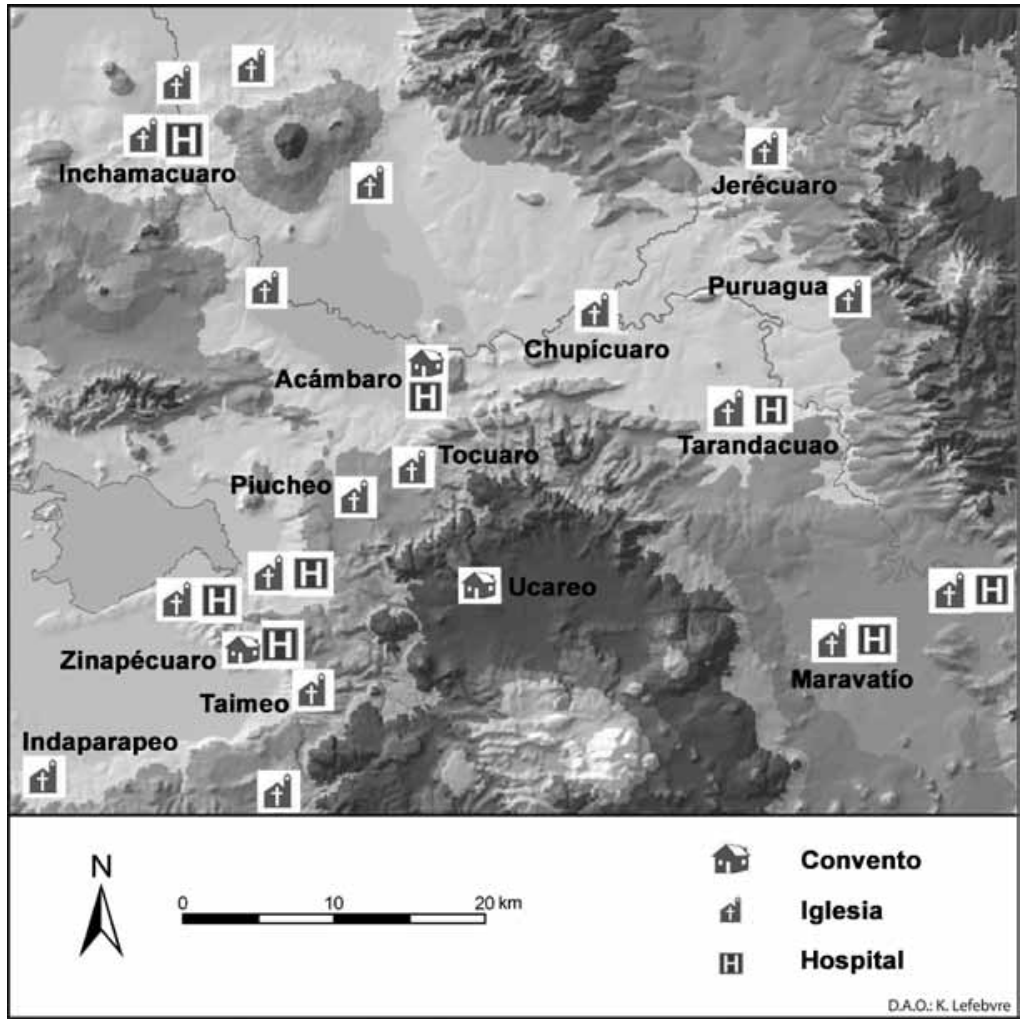

Frente a esta importante obra de construcción, no todos los lugares de culto presentaron la misma inversión humana y económica. En este contexto, nos parece esencial evocar los sistemas constructivos de cada escalón de esta pirámide eclesiástica. El presente estudio propone confrontar diferentes aspectos tipológicos y funcionales de los edificios religiosos, con el objetivo de comprender mejor las relaciones que unen la naturaleza de los materiales de construcción con el estatus jerárquico de cada estructura religiosa.

En un primer momento, se presentará el sistema constructivo de los distintos tipos de edificios religiosos. En el marco de este ar- 
tículo, distinguiremos las iglesias integradas a los conventos de aquellas establecidas en los pueblos secundarios. En un segundo tiempo, se investigarán los aspectos ambientales y antrópicos que influenciaron a los frailes-constructores en la elección de los materiales de construcción.

\section{LOS ASPECTOS METODOLÓGICOS}

De manera general, contamos con poca información sobre las técnicas de construcción de los edificios cívico-religiosos tempranos, y con mayor razón en las provincias periféricas. Son pocos los planos de edificios, los documentos manuscritos con referencias al movimiento de la mano de obra o aquellos con solicitudes de materiales, que se conservaron hasta nuestros días. Por otro lado, los cronistas coloniales sólo describieron de manera muy sucinta las características arquitectónicas de estos edificios, silenciando la mayoría del tiempo los sistemas constructivos para enfocarse en las obras de catequización de los frailes. Frente a esta penuria, era necesario multiplicar las fuentes de información. En la región de Acámbaro, es posible elaborar un primer boceto de esta arquitectura primitiva únicamente mediante el cotejo sistemático de todos los datos disponibles y de indicios, por mínimos que sean, obtenidos a través de la documentación manuscrita, arqueológica y cartográfica.

Los documentos escritos son generalmente los más explotados para este tipo de estudio, pero la fiabilidad de su relato, así como la precisión de los detalles que proporcionan, depende del contexto de su redacción. Las primeras crónicas fueron producidas durante la segunda mitad del siglo xvi. Ofrecen datos que podemos calificar de etnográficos, ya que la mayoría del tiempo, los frailes-autores atravesaron la región para inspeccionar las provincias eclesiásticas y describieron lo que ellos mismos pudieron observar. Es el caso de fray Antonio de Ciudad Real (1976), quien vino a la zona de Acámbaro entre 1584 y $1592^{2}$. Por otro lado, las crónicas más tardías, de los

${ }^{2}$ Antonio de Ciudad Real acompañaba a Alonso Ponce, recientemente elegido comisario general del orden de San Francisco en la provincia del Santo Evangelio, durante la visita de este territorio. 
siglos XVII y XVIII, procuran informaciones más históricas y conmemorativas. Algunos frailes, que tenían la función de cronista, fueron responsables de transcribir la historia de su orden, contando las acciones "heroicas" de los primeros misionarios con la meta de reivindicar la importancia del papel de los religiosos en la conquista de los territorios. Entre estos cronistas se encuentran el franciscano fray Pablo Beaumont de la Purísima Concepción (1932), quien redactó su Crónica de la Provincia de los Santos Apóstoles San Pedro y San Pablo de Michoacán a finales del siglo Xvin y el agustino fray Diego de Basalenque (1985) que acabó su Historia de la provincia de San Nicolás de Tolentino de Michoacán en $1646 .{ }^{3}$ Estos autores se apoyaron en relatos más antiguos y documentos internos de la orden, algunos de los cuales se encuentran hoy desaparecidos. Finalmente, a estos relatos descriptivos, se adjuntan unos cuantos documentos administrativos que mencionan el estado de conservación de los monumentos y las eventuales refecciones necesarias. Estos actos, muchas veces inéditos, complementan las crónicas, que proporcionan informaciones más precisas sobre los sistemas constructivos.

$\mathrm{Al}$ contrario de lo que pueda parecer, a pesar de una ocupación hispánica muy temprana en la región de Acámbaro, la arqueología sólo aporta informaciones puntuales. Esta carencia compete a un problema de investigación. En efecto, la permanencia de los edificios religiosos en un mismo lugar desde el siglo xvi y la falta de apertura de sondeos arqueológicos en los centros históricos de los pueblos coloniales limitan la adquisición de datos a los elementos todavía en elevación. Sin embargo, las importantes transformaciones que ocurrieron durante los siglos XVII y XVIII dejaron pocos espacios a los vestigios de los edificios primitivos. Así, el complejo conventual de Acámbaro es el único ejemplo arquitectural que presenta elementos perennes del siglo Xvi.

${ }^{3}$ Existen crónicas más antiguas, como la de fray Diego Muñoz, Descripción de la Provincia de San Pedro y San Pablo de Michoacán cuando formaba una con Xalisco, escrita en 1585; o la de fray Alonso de la Rea, Crónica de la orden de N. Seráfico P.S. Francisco, provincia de S. Pedro y S. Pablo de Mechoacan en la Nueva España, que fecha de la mitad del siglo XVII. Sin embargo, estas crónicas no tienen el mismo valor informativo para el presente tema. 
Por último, los mapas coloniales, muchas veces infrautilizados, ofrecen otra mirada sobre los edificios primitivos. Después de la conquista del reino tarasco, empezó la colonización y la explotación de la provincia. Desde entonces, se estableció un proceso estricto de adquisición de las tierras con el fin de limitar los conflictos entre colonos europeos o con las comunidades indígenas. Entre las medidas adoptadas, se pedía la realización de mapas a una escala local para completar las diligencias administrativas encaminadas a solicitar tierras o a arreglar litigios territoriales. Los edificios religiosos se volvieron elementos primordiales de estos planos, convirtiéndose en puntos de referencia en el territorio. Más allá de un emblema cristiano, el templo era el marcador de la ocupación hispánica y su mera presencia simbolizaba la totalidad del pueblo. Mientras que muchos dibujantes los figuraron de manera muy sencilla, bajo los rasgos de casas estándares con una cruz encima que permitía identificar su función, otros aportaron detalles arquitectónicos o informaciones sobre la naturaleza de los materiales de construcción.

A través del prisma de esta documentación heterogénea, se estableció un corpus de informaciones sobre el sistema constructivo de los edificios religiosos. A continuación presentaremos estos datos, considerando en un primer tiempo los tres complejos conventuales, luego las iglesias y por fin los hospitales y otras construcciones cívico-religiosas establecidos en los pueblos secundarios de la pirámide eclesiástica.

\section{LOS CONVENTOS, LOS EDIFICIOS PENSADOS PARA PERDURAR}

Entre los tres conventos establecidos en la región (figura 1), el de Acámbaro es, sin duda alguna, el mejor documentado y, por consiguiente, facilita la reconstitución de la evolución arquitectónica.

Todos los documentos escritos coinciden en la fundación precoz y la rápida constitución de un verdadero complejo conventual. Fray P. Beaumont resalta la antigüedad de los conventos de Acámbaro y de Zinapécuaro, de los cuales fecha la primera fase de construcción muy temprano en el siglo xvi: "En este valle [de Valladolid, hoy Mo- 
relia] se fundó un convento por los religiosos franciscanos tan a los principios del descubrimiento de aquella tierra, que nuestro ilustrísimo Gonzaga lo pone inmediato al de Tzitzuntzan. Casi al mismo tiempo se fundó el de Patzcuaro, Acámbaro, Tzinapécuaro, Uruapan, Tarécuaro, y otros muchos que están en el centro de la sierra" (Beaumont 1932, t. 2, 155-156). Más adelante en su crónica, Beaumont (1932, t. 2, 298) transcribe el acta de fundación de Acámbaro y precisa que la construcción del convento, en su etapa original, sucedió entre 1526 y 1527 , es decir, poco tiempo después de que llegaron los españoles a la provincia y fundaron el pueblo hispánico. ${ }^{4}$ Tras haber trazado la trama urbana de la implantación colonial y distribuido los solares entre los indios, los primeros edificios cívicos y religiosos fueron erigidos. Así, la construcción del convento de Acámbaro sucedió antes de la fundación del obispado de Michoacán (1536). Aunque la fecha del establecimiento del convento sea muy precoz, parece totalmente coherente con el objetivo mayor de la conquista espiritual: la avanzada y el arraigo rápido de los misionarios.

La crónica no proporciona descripciones de esta primera etapa de construcción. Sin embargo, los edificios fueron realizados con premura para alojar a los frailes y empezar lo más pronto posible su misión evangelizadora. En consecuencia, con certeza ostentaban características precipitadas y provisionales, se trataba probablemente de construcciones modestas en materiales perecederos, quizás en adobe, una técnica de construcción ampliamente usada por las poblaciones indígenas locales. Pero los conocimientos actuales no permiten especular más sobre la naturaleza exacta del edificio.

Por otra parte, aunque el conjunto conventual fuese de tamaño reducido en un primer tiempo, la descripción somera proporcionada por Beaumont lo presenta de manera explícita como un complejo pensado desde su origen para responder a las principales

${ }^{4}$ Según el Acta de Fundación de Acámbaro, el pueblo colonial fue fundado por los espańoles en 1526. Pero el documento presenta algunas incoherencias cronológicas y un estilo juzgado más tardío, de tal manera que esta fecha está puesta en tela de juicio por varios investigadores (Kubler 1983, 594). El pueblo de Acámbaro existía previamente a la llegada de los conquistadores, quienes lo trasladaron a las llanuras. A pesar de las numerosas dudas que persisten en cuanto a la fecha del desplazamiento del pueblo, una "refundación" temprana es comprobada por numerosos documentos históricos (Lefebvre 2012). 
necesidades de los religiosos: el hábitat, el lugar de culto y el espacio agrícola destinado a satisfacer (por lo menos en parte) a su menester (Beaumont 1932, t. 2, 301). El carácter modesto de los edificios primitivos resultó no sólo de la necesidad por parte de los frailes de implantar rápidamente una base religiosa estable, sino también de las numerosas labores paralelas que tenían que desempeñar. Además de la conquista espiritual, tenían la responsabilidad de establecer una verdadera "comunidad cristiana y europeizada". Así, concentraban funciones religiosas y civiles al encargarse de construir las iglesias, pero también la totalidad de los edificios administrativos del centro urbano, necesarios para el buen desarrollo del pueblo. Arreglaban igualmente los problemas de intendencia fundamentales como el abastecimiento en agua (Kubler 1983, 90). En el caso de Acámbaro, en 1527, es decir, poco tiempo después de la fecha supuesta de fundación del pueblo, frente a la carencia de agua que padecía el pueblo, fray Antonio Bermul (fundador del convento) buscó un ojo de agua que encontró en Tocuaro, uno de sus pueblossujetos. Enseguida, hizo construir un acueducto para traer el agua que debía alimentar Acámbaro y, en particular, que debía servir a la construcción de los edificios (Beaumont 1932, t. 2, 301). Así, frente a la amplitud de sus atribuciones, era necesario remediar lo más urgente por medio de construcciones provisorias: ligeras y rápidamente edificadas.

Poco después, esta etapa primitiva fue seguida por una importante fase de remodelación, que afectó las dimensiones del complejo y la naturaleza de los materiales empleados. Esta reconstrucción global de los edificios fue emprendida con previa solicitud de las altas autoridades administrativas: "[el padre Bermul] Vino el año de mil y quinientos y veinte y nueve, trajo orden de señor Nuño de Guzmán, presidente primero de la real Audiencia de México, gobernó a esta Nueva Espańa, mandó a la real Audiencia que se hagan una iglesia grande o convento grande" (Beaumont 1932, t. 2, 302).

La remodelación del convento participó en una política general de consolidación del arraigo religioso. Los nuevos complejos debían permitir afirmar el carácter duradero de estos polos de cristianización. Según los datos proporcionados por la crónica de P. Beaumont 
(1932, t. 2, 302), esta segunda fase de construcción empezó en 1531 y se acabó en 1532: "lunes a quince de mayo [de 1531], se acabó el cimiento de la iglesia, la puerta para el Poniente. Empezaron a obrar el convento y con mucho riesgo de los enemigos chichimecos, que anda alzados, y se acabó en dicho convento, que fué el año de mil y quinientos treinta y dos años, que el mismo año se puso el Hospital Real de los naturales para los pobres enfermos; e asimismo para los caminantes".

Esta fecha es muy temprana, puesto que, si damos crédito al acto de fundación, la reconstrucción ocurrió apenas seis años después de la refundación colonial del pueblo de Acámbaro y de la edificación del convento original. Sin embargo, estos pocos ańos probablemente fueron suficientes para establecer los acondicionamientos más imperativos. P. Rojas $(1967,50)$ estima que varios detalles arquitectónicos de la capilla del hospital fechan de la mitad del siglo XVI. Esta datación es coherente con la mención histórica del franciscano que ubica su construcción después de la del convento. A pesar de su rapidez, en menos de dos años, la construcción fue realizada en albañilería de piedra y de cal (Beaumont 1932, t. 2, 302; Ciudad Real 1976, 69). Esta inversión importante hace hincapié en la voluntad de perennidad del edificio. Por otro lado, estos materiales permitían ampliar las dimensiones y, de esta manera, obtener el "gran convento" que exigieran las autoridades.

Este primer bosquejo proporcionado por las crónicas coloniales hace eco a las imágenes del edificio representadas en varios documentos cartográficos de la segunda mitad del siglo XVI, en los cuales el convento de Acámbaro aparece como el emblema del mismo pueblo. Varios mapas presentan detalles arquitectónicos bastante precisos para completar los relatos de los cronistas. Desde el fin de los años 1570 , numerosas características propias de este edificio estereotipan su representación y permiten diferenciarla fácilmente de las iglesias cercanas establecidas en los pueblos sujetos, que siguen representadas de manera muy estándar. En un mapa de 1591,5 este

${ }^{5}$ Archivo General de la Nación (AGN), Tierras, vol. 480, cuad. 4, f. 46v, sección mapas, 714 . 
Figura 2. Representaciones coloniales del convento de Acámbaro

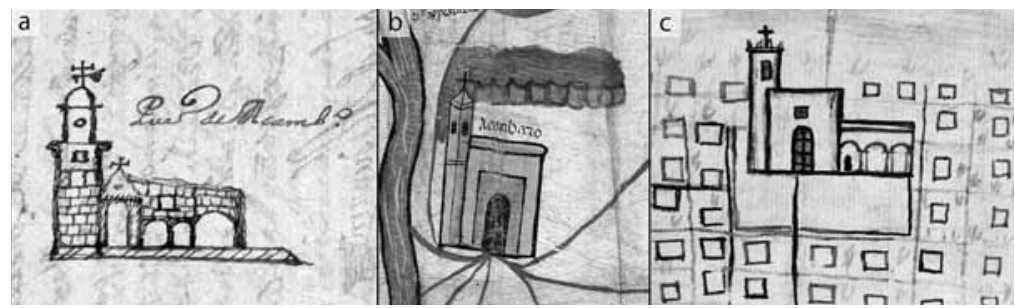

Fuentes: a) AGN, Tierras, vol. 480, cuad. 4, f. 46v, sección mapas, 714; b) Relación Geográfica de Acámbaro, RAH, Departamento de Cartografía y Artes Gráficas, No de registro: 01137. (C) Real Academia de la Historia. España; c) AGN, Tierras, vol. 2,735, 2a parte, exp. 2, f. 10, sección mapas, 1,928 .

complejo toma los rasgos de un edificio esmerado, de tipo europeo, en piedra de sillería (figura 2a). La estructura es de mampostería y constituida de bloques de modulo medio a grande. La figura presenta un templo, identificado como la capilla del hospital de indios, un campanario y una estructura con pórtico. Actualmente, la casi totalidad del convento está cubierta de un estuco que limita las observaciones de los materiales empleados. Pero una fotografía antigua (figura 3) presenta la capilla en segundo plano y enseña claramente muros hechos de bloques escuadrados de gran tamańo, que corroboran la representación cartográfica. ${ }^{6}$

A pesar de haber sufrido numerosas transformaciones desde el siglo XVI, los elementos arquitectónicos perduraron y todavía se observan hoy (figura 4). No pretendemos describir aquí cada elemento arquitectónico del conjunto, sino poner de manifiesto los detalles que permiten comprender su sistema constructivo. ${ }^{7}$ La torre-campanario es ancha. Según P. Rojas $(1967,32)$ esta particularidad permitía sostener la elevación consecuente y dotarla de una apariencia fortificada. La escalera de la torre está horadada por dos ventanas geminadas hechas de piedras de andesita basáltica. La ventana más

${ }^{6}$ Probablemente esta foto fue sacada con motivo de una fase de refacción del estuco de las paredes exteriores del edificio, ya que es el único documento fotográfico que deja observar los bloques de piedra.

${ }^{7}$ Para más informaciones sobre el estudio arquitectónico del conjunto conventual de Acámbaro, recomendamos al lector interesado el trabajo de P. Rojas (1967). 
Figura 3. Fotografía antigua de la fachada del templo del hospital, Acámbaro

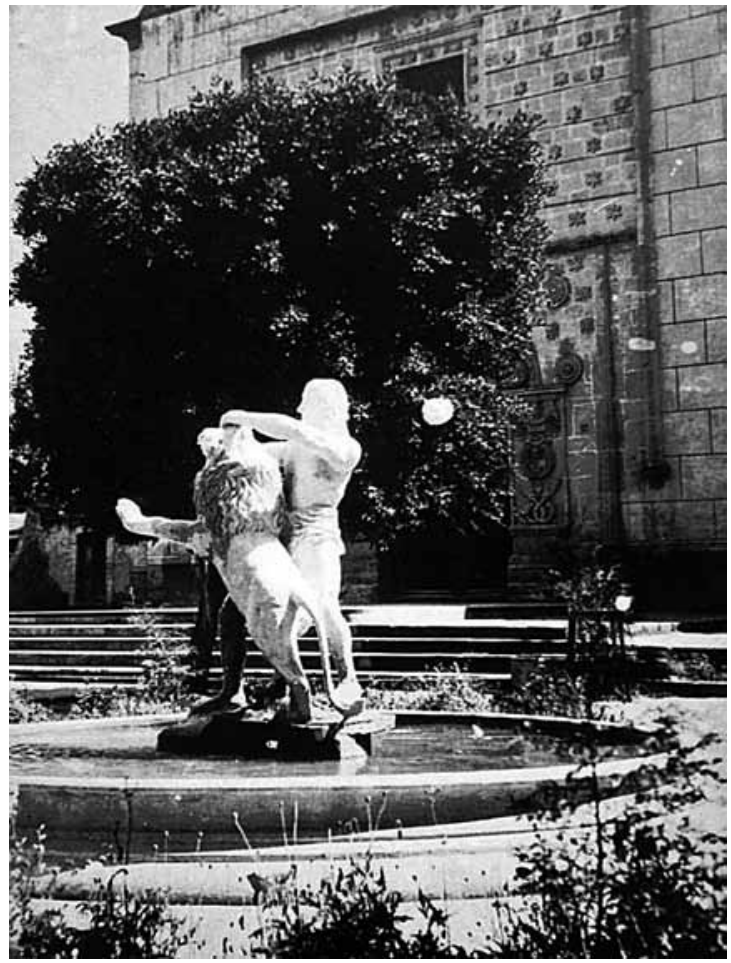

elevada (ubicada en el lado norte) hoy en día está obstruida. El mapa fechado de 1591 da a conocer que gran parte del complejo conventual era de mampostería (figura $2 \mathrm{a}$ ). La torre en su parte inferior está figurada con pequeños rectangulares que materializan con certeza piedras en escuadra. Sin embargo, su parte superior presenta una trama distinta, compuesta de rayas finas y encima una superficie monocroma. Estos materiales son más difíciles de interpretar. Podrían referirse a materiales perecederos, a madera o en la parte más alta a una pared enlucida. El templo del hospital igualmente se construyó con bloques de piedras cuadradas. Aunque no lo muestra el mapa de 1591, en otro documento cartográfico pro- 
ducido en 1580 para acompañar la Relación geográfica de Acámbaro figura un panel decorativo en el pińón del edificio (figura $2 \mathrm{~b}$ ). Esta decoración arquitectónica todavía se puede observar hoy en día (figura 4). Es de gran tamaño y enmarca la puerta monumental y una ventana que la remata. El panel decorativo igualmente está hecho con piedras de andesita basáltica. Su parte superior está salpicado de 58 estrellas con 6 ramas. En su centro se encuentra la ventana rectangular decorada de 19 flores realizadas en un estilo gótico. De cada lado de este ornamento, se ubica un rosetón. P. Rojas (1967, 35) identifica en esta composición un decoro plateresco, muy similar al convento de Actopan. En el mapa de 1591, la ventana tiene la forma de un óculo (figura 2a). Es difícil explicar la diferencia entre esta representación y la realidad observable hoy en día: ise trata de un error del dibujante o el monumento sufrió transformaciones? $\mathrm{Si}$ el conjunto decorativo parece homogéneo desde un punto de vista estilístico, se observa que la ventana corta dos estrellas en su lado izquierdo. A pesar del alineamiento perfecto entre la ventana y la puerta subyacente, es probable que sucedieran cambios arquitectónicos. En el siglo XVI, los templos contaban con pocas ventanas, y estas últimas generalmente eran de pequeño tamaño. Así, la presencia del óculo en el mapa podría representar la realidad histórica. En cambio, la representación de un techo de dos aguas (figura 2a) es muy singular y se distingue totalmente de los demás mapas de la zona que ilustran un techo plano para el templo, tal como aparece todavía hoy en día (figuras $2 \mathrm{~b}, 2 \mathrm{c}$ y 4 ).

El panel decorativo inferior del pińón se divide en varios elementos. Dos jambas enmarcan la puerta, cada una decorada con un medallón que representa a San Pedro que lleva llaves (a la izquierda) y a San Pablo con una espada (a la derecha). Ambos apóstoles descansan en la figuración de un cordón franciscano entrelazado y arriba se encuentra un ángel. Un arco de medio punto que presenta decoraciones vegetales corona la puerta. Al igual que la parte superior, la parte baja de la puerta también contiene una decoración de estrellas con seis ramas y rosetones. Está bordeada de cada lado por columnas comprometidas sin capitel. P. Rojas $(1967,34)$ reconoce en estas decoraciones una influencia mudéjar, gótica y del renaci- 
Figura 4. Vista actual del convento de Acámbaro

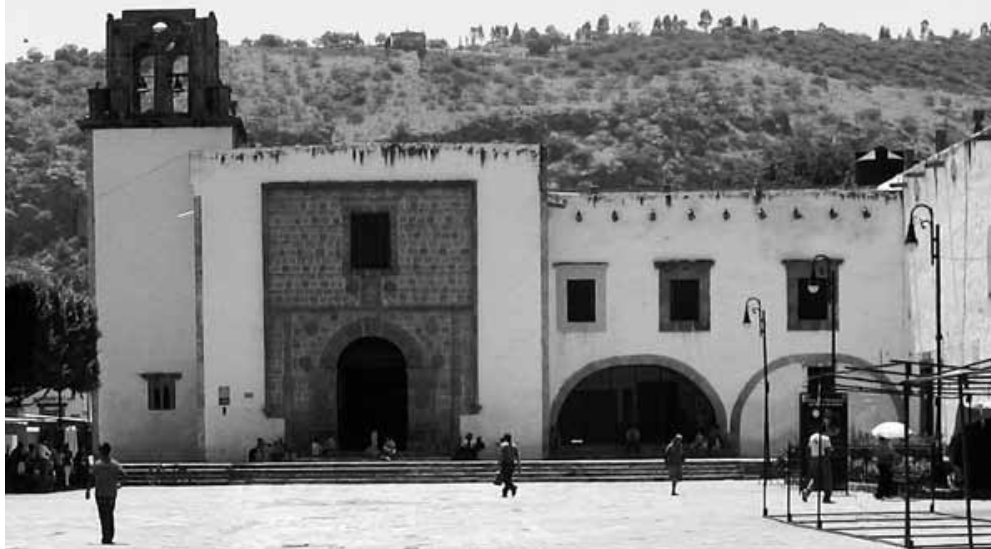

Foto de Karine Lefebvre.

miento temprano, características del siglo xvi. G. Kubler (1983, 501) adjunta que la fachada del templo presenta una combinación de características coloniales e indígenas.

El edificio adosado al sur de la capilla presenta una fachada con un pórtico de tres $\operatorname{arcos}^{8}$ (figuras 2 a y c). Esta estructura es identificada como el claustro del convento, que no aparecía en la fase de construcción anterior. El claustro es el lugar donde se realizaba la predicación, la enseñanza del catecismo, la administración de los sacramentos, además de la celebración de las fiestas (Ciudad Real 1976, 68).

En el mapa de 1591, por encima de los arcos, una ventana supone un segundo piso. Sin embargo, esta elevación fue puesta en tela de juicio por P. Rojas $(1967,51-52)$ quien consideró que esta figuración resaltaba un estereotipo de los lugares de culto michoacanos: "Pese a lo deficiente que puede ser tal dibujo para mostrar la fachada del establecimiento, apunta todos los elementos que describirían a una construcción del género, característica de la segunda mitad del siglo

${ }^{8}$ Los tres arcos se encuentran hoy obstruidos, sin embargo, todavía se pueden ver en la pared las dovelas que forman la cimbra. 
XVI y lo que es más, de la región de Michoacán en la que fueron comunes los piñones rematando las fachadas de los templos, así como las capillas de indios dispuestas en las fachadas frontales". Es verdad que en otros documentos cartográficos, fechados de $1616^{9}$ y $1623^{10}$, tampoco figura esta segunda planta (figura 2c). Este rasgo estandarizado iría acompañado de la figuración del techo de dos aguas ya evocada. Pero la adjunción de rasgos estándares es incoherente con el esfuerzo puesto en los numerosos detalles adjuntados por el autor que parece querer aproximarse lo más posible a la realidad. Entonces, este segundo piso, que existe hoy, queda incierto para el siglo XvI.

Según la representación en el mapa de 1591, el claustro también parece ser de mampostería, por lo menos en parte, puesto que el muro al sur del último arco igualmente representa una superficie rayada. El material empleado no fue identificado.

Es importante subrayar, que otros mapas de la región fechados de $1579^{11}$ y $1580^{12}$ muestran el convento con paredes uniformes, que dan a pensar que la totalidad del edificio estaba enlucido. Más de cuarenta años más tarde, en 1623, otra vez la iglesia está dibujada con piedras. ${ }^{13}$ Esta alternancia de representaciones - entre piedras y enlucido- es difícil de explicar, pero muy seguramente no corresponde a un cambio sucesivo de estilo en un tiempo breve. Es posible que con esta evocación de las piedras a un periodo tardío, el autor hiciera hincapié en la singularidad del monumento: una construcción edificada en piedra en una época temprana.

Los demás elementos del convento -las celdas y el refectorio en particular- no están representados. Por lo tanto, no se puede discutir su sistema constructivo.

Esta segunda fase de construcción es la que se observó durante todo el resto del siglo xvi. Así fue descrita por Ciudad Real (1976, 69) a finales de los años 1580 :

${ }^{9}$ AGN, Tierras, vol. 2,735, 2a parte, exp. 2, f. 10, sección mapas, 1,928.

${ }^{10}$ AGN, Tierras, vol. 3,627, f. 182, sección mapas, 2,512.

${ }^{11}$ AGN, Tierras, vol. 2,809, exp. 27, f. 13, sección mapas, 2,220.

${ }^{12}$ Mapa que acompaña la Relación geográfica de Acámbaro, Biblioteca de la RAH en Madrid, España, Departamento de Cartografía y Artes Gráficas No de registro: 01137.

${ }^{13}$ AGN, Tierras, vol. 3,627, f. 182, sección mapas, 2,512. 
Miércoles quince de octubre salió el padre comisario, ya que amanecía, de Tarandacuau, y andadas tres leguas largas de buen camino llegó a decir misa al pueblo y convento de Acámbaro [...] que se llama Santa María de Gracia, estaba acabado, con su claustro, dormitorios, iglesia y huerta [...] es de mediana capacidad, hecho de cal y canto.

Esta descripción testimonia el cuidado aportado a este monumento muy particular en el pueblo. Contrasta con las técnicas de construcción empleadas por las casas de la gente del común, que Ciudad Real $(1976,69)$ retrata como muy humildes: "Es mediana vecindad la de Acámbaro [...] las casas son de adobes, cubiertas algunas de zoteas de tierra, aunque las más están cubiertas de paja, y así son en todo lo de Michoacán".

Las informaciones que se refieren al convento de Zinapécuaro durante el siglo XVI son menos numerosas. Ningún dato nos ha llegado sobre las características arquitectónicas de la primera etapa de construcción, la de los años 1530, contemporánea con la llegada de los espańoles (Beaumont 1932; Kubler 1983). Aunque muy probablemente este monumento estuvo construido con características modestas como el de Acámbaro, ni su composición, ni la naturaleza de los materiales usados están evocadas en las fuentes coloniales. Unos 50 años más tarde, en 1586, Ciudad Real (1976) visitó el convento de Zinapécuaro, y lo describió de manera sucinta en su crónica: "el convento, el cual es de cal y canto, fuerte y bien hecho, aunque pequeño, pero del todo acabado, con su claustro, dormitorios e iglesia, fundado en un cerrillo; tiene en lo bajo una buena huerta junto a un arroyo, del cual se saca una acequia de agua para regarla”. Un croquis realizado en $1580^{14}$ confirma que casi cincuenta años después de la fundación del convento primitivo, la estructura ya había probablemente sufrido transformaciones importantes, puesto que aparece con rasgos más complejos (figura 5). Aunque no figura todos los detalles proporcionados por la descripción de Ciudad Real, la representación de este edificio rompe con las casas modestas que lo rodean, las cuales parecen construidas con técnicas

${ }^{14}$ AGN, Tierras, vol. 46, exp. 5, sección mapas, 569. 
Figura 5. Representación colonial del convento de Zinapécuaro

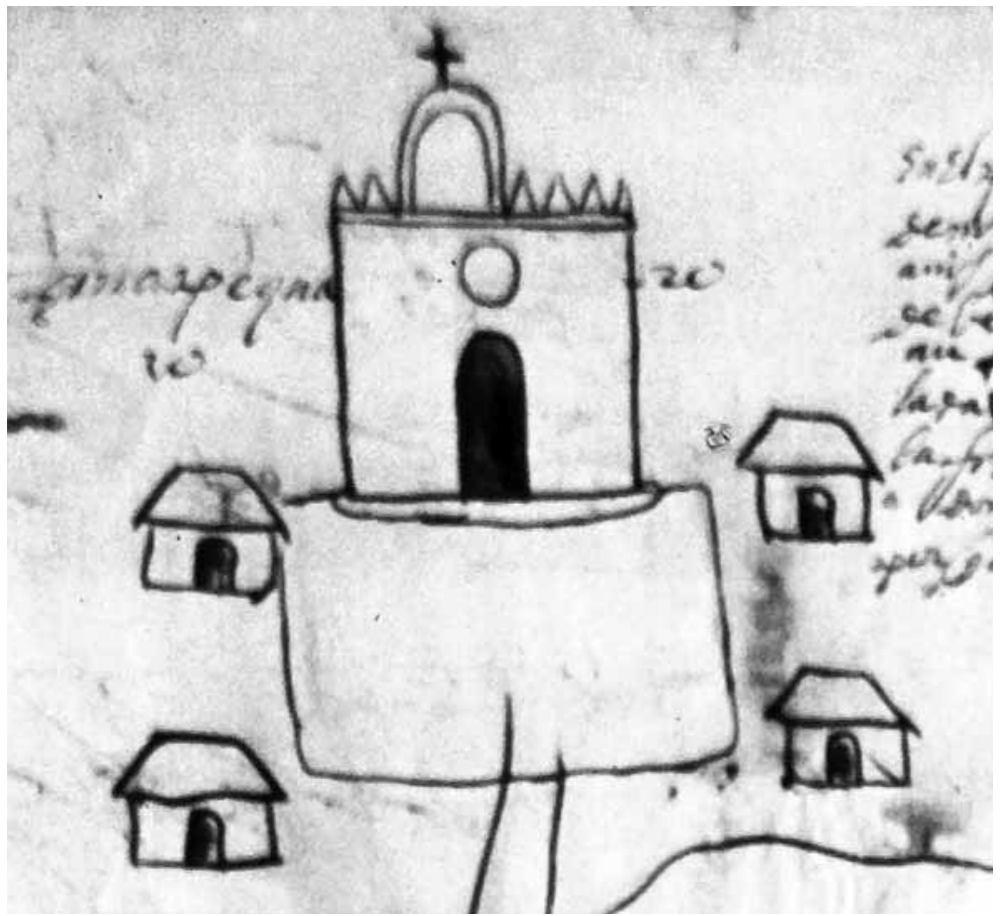

Fuente: AGN, Tierras, vol. 2,737, exp. 11, f. 25, sección mapas, 569.

indígenas. Aunque el dibujo sea muy simplista, proporciona datos originales. La fachada del monumento presenta una puerta monumental rematada por un óculo. El techo plano sostiene una serie de almenas, así como un pequeńo campanil en forma de arco que soporta una cruz. Pero este documento no da indicios sobre el sistema constructivo. Un mapa fechado de $1590^{15}$ representa la iglesia con un doble sistema de construcción. La parte inferior tiene líneas horizontales paralelas, en cambio, en la parte superior figura una superficie monocroma. De esta manera, otra vez la representación muestra un muro de materiales perecederos que descansan sobre

\footnotetext{
${ }^{15}$ AGN, Tierras, vol. 2,681, exp. 17, sección mapas, 1,602.
} 
una estructura de piedra. Se desconoce cuando ocurrió esta segunda fase de construcción. El contexto político-militar puede en cierta medida aclarar este último punto de interrogación. Volveremos a éste, más adelante, en la discusión final.

Finalmente, el convento agustino de Ucareo se diferencia totalmente de los dos primeros. No está representado en los documentos cartográficos encontrados en el AGN, pero Basalenque dedicó un capítulo de su crónica a la fundación de este complejo. Esta descripción debe de ser utilizada con precauciones porque el autor describe el edificio casi un siglo después de su construcción, a partir de lo que escuchó y leyó. En ello, lo presenta tal como fue en los años 1565: "hay convento y hospedería, cada cosa con sus oficinas [...] Puso enmedio del claustro un aljibe al modo de Cuiseo, más éste tiene sus escaleras por donde se baja a él [...] No hay en toda la provincia casa de mejor traza, ni de madera tan linda" (Basalenque 1985, 143).

El convento de Ucareo fue edificado a principios de la segunda mitad del siglo xvi. Según G. Kubler $(1942,8)$, la construcción sucedió entre 1554 y 1557, mientras los frailes agustinos se establecían en la zona. Basalenque sólo evoca una fase de construcción para este edificio. Aunque el agustino haya podido silenciar una etapa preliminar y rudimentaria, tal como sucedió en Acámbaro y Zinapécuaro, la implantación tardía del convento en este sector, casi un cuarto de siglo más tarde que los dos complejos franciscanos, puede explicar que el edificio haya sido inmediatamente pensado y erigido con características duraderas. Además, los frailes franciscanos muy probablemente ya habían edificado una capilla para los servicios. Sin duda esta estructura sirvió de apoyo y de etapa preparatoria a la construcción del complejo conventual. G. Kubler $(1983,626)$ subraya que la iglesia de Ucareo sólo fue reedificada a principios del siglo XVII (1603) y que antes los oficios eran celebrados en un jacal (Basalenque 1985). Quizás este último es el lugar de culto primitivo erigido durante el inicio del siglo XVI.

Según la crónica, el convento de Ucareo fue construido por fray Juan de Utrera que Basalenque califica de "gran arquitecto". Desde un punto de vista funcional, presenta un plan elaborado, con celdas para los religiosos y un claustro. En este sentido, se inscribe total- 
mente en la tradición europea. Pero a diferencia de los otros complejos de la región, éste tiene la particularidad de ser edificado en piedra y, sobre todo, en madera (Basalenque 1985, 142-143).

Desde su origen, el convento fue pensado como un edificio durable y complejo. Aunque oficialmente fue construido en un ańo, Basalenque cuenta el subterfugio que demostró fray Juan de Utrera. El arquitecto tenía originalmente un proyecto de convento muy amplio. Pero el virrey Velasco, que supo de éste, le pidió que rebajara sus ambiciones para edificar un monumento más modesto, "que se acabase en poco más de un año” (Basalenque 1985, 143). Deteniendo oficialmente las obras, Utrera hizo preparar y labrar todos los materiales sin interrupción. De esta manera, cuando vino el momento de edificar el monumento, la obra se realizó muy rápidamente, puesto que sólo faltaba armar los materiales, lo que fue concluido en un año. G. Kubler $(1983,131)$ adjunta que este escalonamiento en el tiempo es una característica agustina, y que es común que las obras arquitectónicas de los agustinos se extendieran por periodos largos de construcción, incluso en ocasiones durante varias generaciones.

\section{LAS IGLESIAS. LOS MONUMENTOS EFÍMEROS}

Las informaciones relativas a las iglesias son generalmente escasas y poco expansivas, puesto que los cronistas sólo registraron su existencia sin detallar realmente su apariencia. Esta falta de interés se explica probablemente por el lugar segundario de estos edificios en la jerarquía de los monumentos religiosos. Los autores se concentraron en los conventos, verdaderos lugares de vida de los frailes y corazones de las redes eclesiásticas locales. Las informaciones sobre los templos realmente explotables proceden de mapas coloniales y de actos administrativos que relatan problemas de alteración de los edificios. Por lo tanto, ignoramos sus fechas -o periodos- de edificación. Con certeza, éstas fueron muy precoces, probablemente en los meses y ańos que siguieron a la implantación de los conventos, porque los templos jugaban un papel de intermediarios en el proceso de cristianización. Permitían a los religiosos ir al encuentro de las poblaciones para infundirles la fe cristiana. Así, por iniciativa de los 
frailes al mando de los conventos se construyeron templos en su parroquia respectiva. El corpus histórico da a conocer que a finales del siglo Xvi, la mayoría de los pueblos de la región ya tenían un lugar de culto propio (figura 1). Estas construcciones permitían marcar el paisaje y los espíritus con el sello de la religión cristiana. No se trata de una metáfora sino de una realidad física. La edificación sistemática de las iglesias participaba en la lucha contra las antiguas religiones politeístas. Por tanto, fueron construidas en todas las categorías de asentamiento: en los pueblos-sujetos, tal como Inchamacuaro o Tarandacuao, en las aldeas, a imagen de Santa Clara o de Puruagua, pero también en las cabeceras en las cuales no se habían establecido conventos, es decir, en Maravatío y Taimeo. Desde entonces, parece interesante observar si la gran diversidad de estatus administrativos entre los asentamientos tuvo consecuencias en la estructura de los templos y su evolución a lo largo del siglo XVI.

Desde la llegada de los religiosos, en los pueblos, una estructura, incluso sumamente ligera, era elevada. El acto de fundación de Acámbaro señala que, llegando a Tocuaro en busca de agua por Acámbaro, fray A. Bermul aprovechó su presencia para "refundar" el pueblo según los ritos coloniales: "una semana estuvo el padre Fray Antonio Bermul en Tocuaro, y en medio de un llanito, mandó el padre, que se pusiese una enramada para celebrar la santa misa todos los días y enseñando a estas cuarenta familias. No eran bautizados, que el padre fray Antonio los bautizó, los casó" (Beaumont 1932, t. 2, 301). El religioso ordenó la edificación de una estructura muy rudimentaria para realizar los primeros oficios. ${ }^{16}$ Aunque se trataba más de un abrigo aprovisionado que de una verdadera estructura religiosa, esta construcción puede ser considerada como el primer lugar de culto de Tocuaro. En este sentido, aparece que los pueblos de la parroquia seguían un proceso similar al de los asentamientos que albergaban los conventos. La primera labor de los misionarios era celebrar una misa y construir un lugar para hospedar los oficios divinos.

\footnotetext{
${ }^{16}$ Si bien, la edificación de enramadas en época temprana de la Colonia es una práctica muy común en numerosas partes de México, en Michoacán parece haber tenido un peso más importante. Lo atestigua su construcción en los atrios durante las festividades religiosas todavía hoy, por ejemplo, en Patambán.
} 
Rápidamente, estas estructuras provisionales fueron sustituidas por edificios más duraderos (aunque todavía modestos). Casi no poseemos informaciones sobre el sistema de construcción de los lugares de culto establecidos en los pueblos más pequeños para el siglo XVI. Toda la información se concentra en los asentamientos que tienen una importancia administrativa (como las cabeceras) o económicas. En los mapas coloniales, las iglesias menores tienen siempre una representación muy estandarizada y sencilla que no permite determinar los materiales empleados. Este tipo de figuración podría suponer que las técnicas de construcción usadas para estos templos eran similares a las de las casas de la gente del común, quizás con muros de adobe y techos en vegetales. Sin embargo, es difícil distinguir una figuración elemental y estereotipada de un dibujo voluntariamente sencillo con fin de acercarse más a la realidad. Pero, un documento cartográfico fechado de $1589^{17}$ representa a las iglesias de Taimeo y de Otzumatlán con cierto realismo (figuras 6 a y b). Estos dos pueblos no son cualesquiera, se trata respectivamente de una cabecera y uno de sus pueblos-sujetos más importantes, por la presencia de minas de plata. En este mapa, las iglesias que simbolizan las localidades parecen de tamaño importante, puesto que la puerta principal está rematada por dos ventanas, que señalan un techo alto. La iglesia de Taimeo está flanqueada por dos torres campanarios, una de cada lado de la puerta principal, mientras que la de Otzumatlán, de tamańo ligeramente inferior, posee una torre campanario, así como un pequeño campanil en arco que corona el techo. Eso da a pensar que a finales del siglo XVI, las iglesias de los pueblos sujetos del convento más importantes, por razones administrativas o económicas, podían presentar formas complejas y extensiones arquitectónicas. Otro mapa realizado en $1590^{18}$ figura la parte baja del templo de Taimeo con líneas paralelas rayadas, que podrían simbolizar la existencia de un basamento de piedra (figura 6c). En cambio, la parte superior muestra una superficie uniforme que podría ser identificada como una pared enlucida. Esta distinción otra

${ }^{17}$ AGN, Tierras, vol. 2,729, exp. 18, f. 296, sección mapas, 1,915.

${ }^{18}$ AGN, Tierras, vol. 2,681, exp.17, sección mapas, 1,602. 
Figura 6. Representación colonial de las iglesias de Taimeo (a y c) y de Otzumatlán (b)

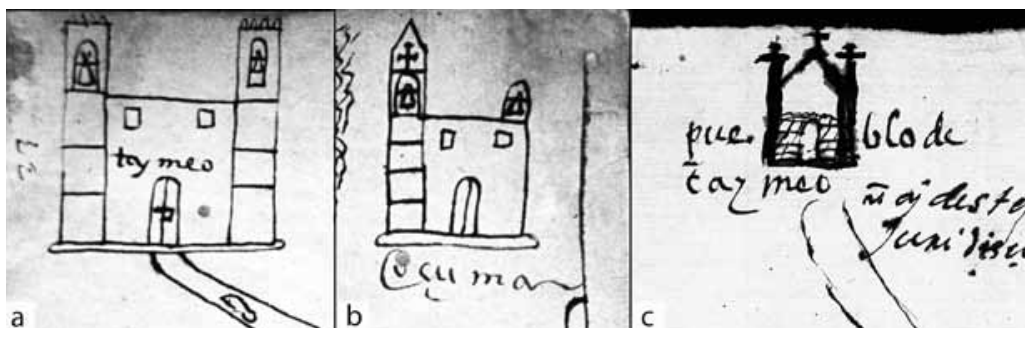

Fuentes: a y b) AGN, Tierras, vol. 2,729, exp. 18, f. 296, sección mapas, 1915; c) AGN, Tierras, vol. 2,681, exp. 17, f. 24, sección mapas, 1,602.

vez sugiere la edificación de un muro que asocia dos sistemas de construcción distintos: los muros con materiales perecederos, probablemente con adobe cubierto de enlucido, que se apoyaba sobre un basamento de piedras.

Otros testimonios escritos evocan los templos edificados en las cabeceras. En 1591, frente al estado de deterioro de su iglesia, los indios de Maravatío pidieron el permiso de cambiar el servicio que daban a las minas de Tlalpujahua por trabajos de refección del monumento. Así, el documento precisa que:

la iglesia que tienen donde se celebra los divinos oficios esta mucha parte della por el suelo [...] el cura y beneficiado que tiene a su cargo su conversión y doctrina no quiere acudir a decir misa en el d[ic]ho pu[ebl]o por el peligroso que corre su persona en edificio tan viejo [...] [es necesario] hacer otra iglesia nueva para este efecto tienen necesidad de ser reservados del servicios personal que dan a las minas de tlalpuxagua por el tiempo que darare la obra della. ${ }^{19}$

Este acto hace hincapié en la vetustez de un edificio calificado de "viejo", aunque fue construido menos de 65 años antes. El "ciclo de vida" corto del monumento puede atribuirse en parte a la presencia

${ }^{19}$ AGN, Indios, vol. 5, exp. 982, f. 323. 
de numerosos ojos de agua y de una ciénaga en las inmediaciones del pueblo. ${ }^{20}$ La humedad ambiente probablemente aceleró la degradación del monumento. Sin embargo, el templo será reconstruido sobre un plan idéntico y con muros de adobe y cubierta de tejamaniles, ${ }^{21} \sin$ añadir cambios mayores. ${ }^{22}$

De la misma manera, en 1619, un acto autoriza a los naturales de Indaparapeo a permutar su servicio personal a las minas de Otzumatlán contra la restauración de su templo: "la yglesia del d[ic]ho pueblo esta descubierta y la mayor parte della cayda y que no se celebran [...] los oficios divinos". ${ }^{23}$

Estos pocos ejemplos demuestran que existe una diferencia morfológica entre las iglesias establecidas en los pueblos de baja importancia administrativa y económica y los centros mayores, tipo cabecera. Esta influencia se refleja a través de la presencia de elementos adicionales, tal como los campanarios, mientras que templos muy sencillos fueron erigidos en los pueblos menores. En cambio, el rango en la pirámide administrativa no tiene incidencia en los materiales usados. Un siglo después de la implantación de los religiosos en la provincia, todos los templos establecidos en los pueblos segundarios de la parroquia siguen edificados en materiales perecederos: en adobe, a veces asociado a un basamento de piedra, al igual que las casas de la gente del común. Resultó que los edificios religiosos no se benefician de un tratamiento particular, sino al contrario se inscriben en una técnica de construcción idéntica a la totalidad del pueblo. ${ }^{24} \mathrm{Su}$ construcción parece responder a un imperativo: una edificación rápida y con el menor costo, y eso cual sea el estatus del asentamiento.

La naturaleza de estos materiales y el desplazamiento de los pueblos prehispánicos hacia los valles, con frecuencia más húmedos, e incluso a veces en zonas pantanosas (en el caso de Maravatío), fueron el origen de importantes daños. A diferencia de los conventos,

${ }^{20}$ AGN, Tierras, vol. 1,162, exp. 9 .

${ }^{21}$ Los tejamaniles son tablas delgadas y cortadas en listones que se colocan como tejas en los techos de los edificios (Diccionario de la Real Academia Española).

${ }^{22}$ AGN, Indios, vol. 5, exp. 1,106, f. 351.

${ }^{23}$ AGN, Indios, vol. 9 exp. 131, fs. 69-69v.

${ }^{24}$ AGN, Tierras, vol. 1,162 , exp. 9. 
estos edificios no se mantuvieron a través del tiempo. Su deterioro avanzado menos de cien años después de su construcción, no indujo reestructuración o cambios mayores en sus dimensiones o en los materiales de construcción empleados. Así, la fase de arraigo, durante la cual los edificios fueron construidos de manera modesta, en muchos casos se continuó hasta principios del siglo XVII.

\section{LOS HOSPITALES Y OTRAS CONSTRUCCIONES CÍVICO-RELIGIOSAS}

El caso de los hospitales de indios es más complicado, por la escasez de los datos y la diversidad aparente de los materiales empleados.

Los conquistadores trajeron con su paso numerosas enfermedades que afectaron severamente a las poblaciones indígenas de Nueva España. Varias epidemias se propagaron: la viruela en 15191520, el sarampión y la varicela en 1531, la rubeola en 1538-1539 (Rodríguez Álvarez 2009, 174). A partir de 1545, el tifus, la tifoidea y la peste siguieron diezmando los pueblos. En 1555, frente a la caída demográfica drástica, el primer concilio de México requirió la construcción de estructuras hospitalarias en cada pueblo para hospedar a los enfermos y a los viajeros (Ricard 1986, 256). Sin embargo, en su etapa temprana (siglos XVI y XVII), la función de los hospitales no solamente estaba relacionada con la atención medica, para enfrentar a las epidemias y a la alta tasa de mortalidad, sino también jugaba un papel administrativo de gran importancia, ya que también era la sede del cabildo de indios, la custodia de documentos oficiales del pueblo y el almacén del tributo. Además, proporcionaba un espacio físico y arquitectónico para el desarrollo de actividades artesanales y sociales cotidianas. Por lo tanto, estas estructuras estaban en medio de la vida cotidiana del pueblo (Warren 1977; Muriel 1990).

Mientras estas estructuras no se generalizaron a la totalidad de los asentamientos, se multiplicaron considerablemente en el territorio. La provincia de Michoacán es una de las zonas donde la red hospitalaria tuvo más importancia, gracias al impulso del obispo Vasco de Quiroga. Ciudad Real $(1976,68)$ indicaba que: 
En todos los pueblos de la provincia de Michoacán, así en la parte de Michoacán como de Xalisco, donde hay convento nuestro o de San Agustín o residen clérigos, y aun en los demás pueblos como no seran demásiado pequeños, tienen los indios un hospital y en él se curan los enfermos del pueblo, y darles de comer tienen allí muchos indios e indias, y allí los curan y les administran los santos sacramentos de la penitencia, viático y extremaunción.

Estos refugios fueron edificados bajo la egida de los religiosos en todas las categorías de asentamientos: junto a los conventos en los pueblos mayores, pero también en numerosos poblados segundarios (figura 1). A pesar de esta gran difusión, los datos relativos a su morfología y su sistema constructivo son casi inexistentes. Sin embargo, podemos distinguir dos escenarios. Primero, los hospitales asociados a los conventos, como en Acámbaro. Esta estructura, que ya mencionamos por su templo, exhibe características perennes. Sin embargo, en el mapa que representa a Acámbaro en $1591^{25}$ también figura una estructura más modesta que se identifica como una estancia del hospital de los indios otomíes. El dibujo pone de manifiesto un edificio de forma sencilla, erigido con bloques probablemente de adobe. $\mathrm{Su}$ techo, de dos aguas, parece ser cubierto con vegetales.

Otro mapa fechado de 1614 enseńa el hospital de Tarandacuao, un pueblo sujeto de Acámbaro $^{26}$ (figura 7). Esta representación es muy similar a la de la iglesia situada a su lado, pero de tamaño inferior. Tiene la forma de una casa con un techo a doble aguas, rematado por una cruz. El color café de los muros da a pensar que fueron construidos en adobe.

Obviamente, los documentos que mencionan el sistema constructivo de los hospitales son insuficientes, pero abren algunas pistas de reflexión. Al parecer, los materiales de construcción empleados dependían no sólo del estatus del asentamiento en el cual estaba implantado, sino también de la función del edificio. De esta manera, la distinción entre el templo de Acámbaro y el de Tarandacuao

${ }^{25}$ AGN, Tierras, vol. 480, exp. 1, cuad. 4, f. 46v, sección mapas, 714.
${ }^{26}$ AGN, Tierras, vol. 2,680, exp. 29, f. 31, sección mapas, 1,594. 
Figura 7. Representación colonial de la iglesia y del hospital de Tarandacuao

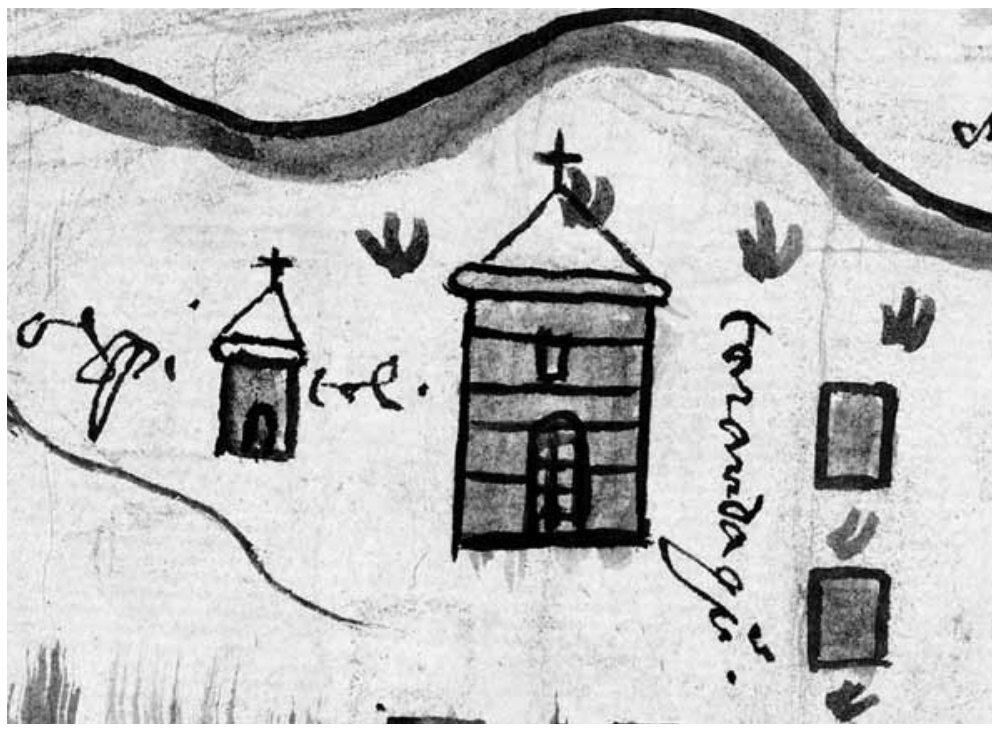

Fuente: AGN, Tierras, vol. 2680, exp. 29, f. 31, sección mapas, 1594.

está claramente en relación con el lugar de los pueblos en la jerarquía eclesiástica. Esta concordancia es tanto más fuerte que el hospital y el lugar de culto estaban estrechamente vinculados, puesto que los mismos misionarios administraban estos refugios. No obstante, en el seno de los pueblos mayores, tal como Acámbaro, la totalidad de los edificios que componían el hospital no era homogénea. La elección de los materiales usados estaba relacionada con su función. Mientras la atención y la inversión humana y financiera se enfocaron en el templo, la estancia fue construida de manera más modesta. El primer objetivo del hospital era hospedar enfermos y pobres, pero también tenía un papel de abastecimiento (maíz, carne...). A fin de responder a estas necesidades, el hospital y las comunidades obtenían tierras agropecuarias. A partir de los mapas, aparece que los edificios relacionados con la función agrícola, aunque estuviesen bajo la gestión de los frailes, no fueron objeto de una inversión ma- 
yor. Aunque no tenemos informaciones, es posible que otras estructuras relacionadas con los hospitales, en particular, los dormitorios o comedores siguieron un destino similar, y fueron edificados con técnicas más modestas y tradicionales.

\section{Discusión}

Con el fin de comprender mejor los motivos que influenciaron la selección de los materiales de construcción de cada edificio religioso, es necesario examinar dos ejes: el aspecto ambiental de la región y el aspecto histórico.

La influencia del entorno natural no debe de ser subestimada. La región de Acámbaro es una zona de transición entre las amplias llanuras del Bajío que se extienden al norte y los contrafuertes de la meseta tarasca al sur. Se forma de un mosaico de paisaje altamente contrastado compuesto de sierras altas, cerritos, llanos y valles. La gran variedad del paisaje tuvo repercusiones en la naturaleza de las materias primas disponibles y, de hecho, sobre los sistemas de construcciones.

Hasta ahora, se desconocen fuentes de extracción de piedra explotadas durante el siglo Xvi en las zonas de valles y llanuras. ¿De dónde provienen las piedras empleadas desde entonces para la construcción de los edificios de mampostería o de los basamentos en los pueblos nuevos? Es posible que la gran mayoría de ellas provenga de las antiguas implantaciones, en particular, de las estructuras piramidales. En 1540, Molina explicaba que numerosos edificios eran construidos por medio de materiales recuperados después de la demolición de templos prehispánicos. Este desmontaje tenía un doble objetivo. Primero, la desaparición completa de las pirámides favorecía el abandono y el olvido de las prácticas cultuales indígenas. Por otro lado, daba acceso a un yacimiento de materiales de construcción fácilmente explotable. La distancia de desplazamiento reducida entre los asentamientos prehispánicos y coloniales, que generalmente no rebasaba un kilómetro y medio, facilitaba el acarreo de los materiales hasta las nuevas zonas de construcción (Lefebvre 2012). En la región, las estructuras monumentales indígenas estaban principalmente hechas de bloques de piedras volcánicas - de tezontle y de 
Figura 8. Petrograbado ubicado en el muro de contención norte del templo del Hospital, Acámbaro

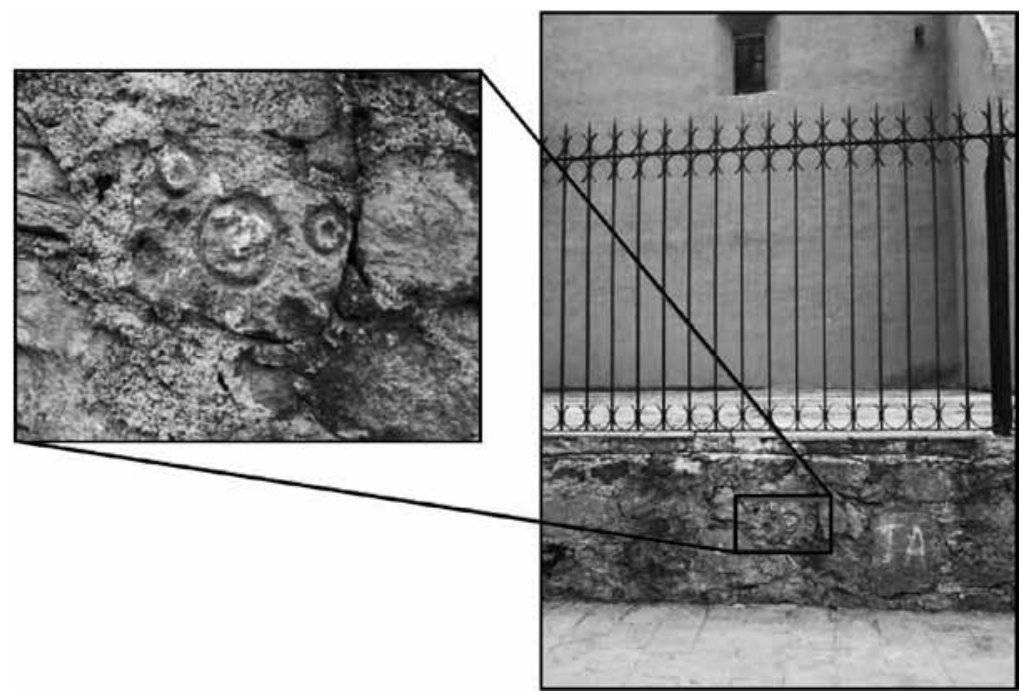

Foto de Karine Lefebvre.

basalto- de tamańo medio (aproximadamente $30-40 \mathrm{~cm}$ de largo), mientras que las piedras de grandes dimensiones eran más escasas. En el caso del convento de Acámbaro, es posible que una parte de los muros haya sido realizada a partir del desmontaje de las estructuras piramidales de sitios cercanos, en particular, de los ubicados en los cerros del Chivo y del Toro. De hecho, una piedra de un muro de contención que rodea la capilla del hospital, en su lado norte, presenta un petroglifo, que figura círculos concéntricos (figura 8).

Ahora bien, el tezontle es una piedra porosa y ligera, que G. Kubler $(1983,169)$ caracterizaba de "inapropiada para la talla elaborada para la unión de arcos y para las esquinas expuestas a uso constante o erosión". Por lo tanto, los bloques de sillería que conforman los muros, el portal del templo, que recibía numerosas decoraciones esculpidas, igual que las dovelas de los arcos del pórtico han sido hechos con piedras distintas y de mejor calidad. La naturaleza de los grandes bloques de piedra no pudo ser identificada, porque 
estos últimos son actualmente inaccesibles, cubiertos por el enlucido. En cambio, las piedras del portal y de los arcos fueron identificadas como andesita basáltica. Se trata de una roca bastante común en la región. Aunque hasta ahora ninguna zona de extracción está registrada en el siglo XVI, es importante subrayar que en las inmediaciones de Acámbaro, al oeste del cerro el Chivo, una cantera actualmente está en explotación. Por lo tanto, es muy posible que la andesita basáltica del templo provenga de un sector cercano. A pesar de su cercanía, con certeza, el valor de las piedras de sillería hacía este tipo de construcciones escaso y por ello gozaba de un estatus superior.

En cambio, el tezontle era perfectamente adaptado a la construcción de basamentos de piedras. Es probable que en el caso de Taimeo, cuyo templo dispone de este tipo de acondicionamiento, las piedras provengan únicamente del antiguo asentamiento. Pero, ¿por qué la agregación de basamento no se generalizó a la totalidad de los templos? Para explicar tal situación cabe aducir dos motivos. Primero, la ausencia de estructuras monumentales en algunos asentamientos prehispánicos. En vísperas de la Conquista, en los pueblos más pequeños -tipo aldea-, no se observó ningún vestigio monumental o indicios de su presencia en el pasado. Así, en Piucheo o Tocuaro, la religión se practicaba a una escala individual como testimonia el descubrimiento de numerosos fragmentos de pipas, verdaderos marcadores de prácticas religiosas durante el Posclásico tardío. Por otro lado, en el caso de Maravatío, la ausencia de basamento se explica por el traslado excepcionalmente importante entre el asentamiento prehispánico y el colonial. El pueblo original de Maravatío fue identificado como el sitio de Santa Rita, establecido sobre los contrafuertes orientales de la sierra de Ucareo, aunque la implantación colonial fue transferida a más de $5 \mathrm{~km}$ al este, en el llano hoy conocido como Casa Blanca. Este alejamiento considerable quizás resultó del relieve marcado alrededor del asentamiento prehispánico, que no concordaba con los criterios de asentamientos hispánicos. A pesar de la presencia de estructuras monumentales imponentes en el sitio de Santa Rita, las piedras no fueron transferidas para construir los edificios hispánicos. Además, el estableci- 
miento del pueblo colonial en un sector desocupado previamente a la Conquista ${ }^{27}$ también restringió la disponibilidad de piedras. La implantación del asentamiento en un llano pantanoso habría requerido el establecimiento de un basamento de piedra a fin de limitar el deterioro del adobe por la humedad, pero los materiales de construcción disponibles en el entorno próximo no lo permitieron.

¿Por qué no todos los pueblos coloniales ubicados cerca de un sitio arqueológico que dispone de estructuras monumentales aprovecharon los materiales para erigir edificios completamente de mampostería? Como ya lo mencionamos, la naturaleza de las piedras disponibles podía constituir un obstáculo para una elevación importante. Pero existe otro elemento mayor que debe ser tomado en cuenta: la argamasa. G. Kubler (1983) hace hincapié en los problemas de abastecimiento de cal, necesaria en la constitución del mortero de los edificios de mampostería durante el siglo XVI. En la región de Acámbaro, los testimonios de su producción son muy escasos. El proyecto arqueológico Chupícuaro puso de manifiesto la extracción de carbonato (el origen de la cal) en los complejos hidrotermales de Las Cazuelejas y de Los Tules, en el sector de Puruagüita (Darras 2000, 19). Los arqueólogos determinaron una explotación prehispánica y después colonial en Las Cazuelejas. Los periodos más antiguos fueron identificados por la presencia de tepalcates y de herramientas de obsidiana, basalto, andesita y calcedonia, empleados para extraer y moler el mineral. Estos artefactos se encontraron encastrados en la calcita. Una fase de explotación más reciente fue fechada de la época colonial a partir de la orientación del frente de corte, paralelo al parcelario de las haciendas de Puruagua y de Santa Inés, construidas en el siglo XviI y establecidas a menos de $5 \mathrm{~km}$. A esto se ańade la identificación de varias caleras (tres cerca de Las Cazuelejas, y una no muy lejos de Los Tules), pero su actividad se ubica entre los siglo XIX y xx, según la memoria oral. Así, no hay pruebas que respalden su utilización durante el siglo XVI. En cambio, cuatro documentos indican claramente la existencia de caleras

${ }^{27}$ Estudios arqueológicos recientes pusieron de manifiesto que si bien las llanuras eran explotadas, los sitios se encontraban en las alturas durante el Posclásico tardío (Lefebvre 2012). 
en la zona durante el primer siglo de la colonización. Los dos primeros, las crónicas de Beaumont (1932) y de Basalenque (1985), se refieren a la presencia de un horno de cal en las obras de los conventos de Acámbaro y de Ucareo respectivamente. Estas menciones sugieren una presencia efímera, el tiempo necesario para la construcción de los edificios. Otros documentos, conservados en el AGN, atestiguan otras dos caleras al pie de la sierra de Los Agustinos ${ }^{28}$ y de la sierra de Ucareo cerca de Araró. ${ }^{29}$ Estos hornos tienen la particularidad de encontrarse a proximidad de importantes zonas forestales, pero también de las vías de comunicación importantes que permitían llevar el material a los pueblos más notables. La escasez de cal hace de su uso el marcador de un edificio importante, se vuelve el atributo de los grandes proyectos arquitectónicos. Para oponerse a esta penuria, las construcciones más sencillas frecuentemente eran elaboradas con argamasa de adobe, más económico y tradicional, puesto que esta técnica se encuentra comúnmente en los monumentos indígenas locales. Sin embargo, esta técnica de substitución, supervivencia prehispánica, no permitía erigir elevaciones importantes, y por consiguiente su uso era limitado a edificios bajos y a basamentos.

Los materiales de construcción disponibles en la sierra son muy distintos. En la región, el importante escalonamiento ecológico contribuye a la variedad de los especímenes vegetales. Mientras que en las llanuras se desarrolla principalmente una cubierta vegetal baja, las cimas se caracterizan por bosques mixtos compuestos de robles y de pinos. Estas especies fueron tanto más importantes que las necesidades de madera de gran dimensión crecían a medida que se instalaron los colonizadores. Servían para la creación de los pueblos coloniales y de los puentes, o también para apuntalar las galerías de las minas.

La explotación de la madera ya era importante previamente a la llegada de los españoles. El territorio de Ucareo aparece desde el Posclásico tardío como una de las cabeceras más pobladas de la re-

${ }^{28}$ AGN, Mercedes, vol. 18, fs. $154 \mathrm{v}-155$.

${ }^{29}$ AGN, Mercedes, vol. 22, fs. $25 \mathrm{v}-26 \mathrm{v}$. 
gión (Paso y Troncoso 1905, t. 1, 294). La documentación histórica revela que numerosos pueblos de este sector se dedicaron a la explotación forestal a lo largo de la época prehispánica y del siglo xvi. Un testimonio del ramo Congregación, conservado en el AGN, pone de manifiesto la utilización económica de los bosques. Este documento $^{30}$ acuerda a los pueblos de Santa Ana, San Ildefonso y Los Carpinteros el derecho de reagruparse en Santa Ana y no en Ucareo. Primero, el nombre mismo del poblado de Los Carpinteros llama la atención porque se refiere directamente a trabajo de la madera. Por otro lado, en los argumentos aportados para sostener el reagrupamiento de las poblaciones en Santa Ana, los principales y los naturales de estas localidades precisan "tener allí cerca la comodidad del monte [...] donde hay gran demanda y salida para los tejamaniles que hacen lo cual les vale mucho dinero". La utilización del argumento económico para oponerse a la congregación prevista por las autoridades hispánicas y el hecho de que se tomó en cuenta testimonian la importancia de esta actividad. En 1592, los vecinos de Taximaroa se quejaron de los de Ucareo que "destruyen los montes haziendo vigas y tablas para granjerias y llegando hasta la estancia de San Mateo su sujeto [de Taximaroa] con el daño". ${ }^{31}$ En este caso, la explotación forestal se refiere claramente a la producción de materiales de construcción.

La geografía y la cubierta vegetal de este sector suscitaron una verdadera dinámica de población alrededor de la industria de la madera. Además, los terrenos andesíticos y basálticos permiten la extracción de bloques de piedra. En cambio, la naturaleza del suelo, así como su erosión por efecto de las lluvias y de las pendientes importantes, vuelven la zona desfavorable para la producción de adobe. Por consiguiente, la elección de los materiales empleados para la construcción del convento de Ucareo parece totalmente adecuada con el contexto ambiental muy particular, la madera y las piedras son los recursos más disponibles. El uso de la madera no debe de ser interpretado como el testimonio de un edificio modesto y precipita-

\footnotetext{
${ }^{30}$ AGN, Congregaciones, vol. Único, exp. 164 fs $87 \mathrm{v}-88$.

${ }^{31}$ AGN, Indios, vol. 6, exp. 92, fs. 23-23v.
} 
do, sino más bien como la adopción de la tradición arquitectónica local. Este edificio era tan pensado y elaborado como los de Acámbaro y de Zinapécuaro. Su construcción es refinada hasta los más mínimos detalles como lo subraya Basalenque (1985): "No hay en toda la provincia casa [...] de madera tan linda [...] vigas tan bien labradas", y el uso de argamasa de cal, ya mencionada, apoya esta conclusión.

Paralelamente a esta influencia ambiental e histórica, la situación político-militar local del siglo Xvi tuvo igualmente repercusiones en el sistema constructivo. Aunque los criterios de elección de los materiales de construcción estaban obviamente relacionados con la jerarquía entre los conventos y los templos edificados en los pueblos secundarios, estos criterios iban aún más allá. Durante el siglo XVI, la zona de Acámbaro sufrió numerosos ataques. Con motivo de su estancia en Acámbaro, fray Antonio de Ciudad Real $(1976,159)$ contó que "anduvieron muchos indios por orden de la justicia con arcos y flechas a punto de guerra, guardando la iglesia por respeto a los chichimecas que no están lejos de allí, de la otra banda del Río Grande, para que si acaso viniesen no los hallasen descuidados, porque en semejantes solemnidades y fiestas suelen ellos hacer sus saltos". Estas incursiones, que persiguieron a lo largo del siglo xvi, eran realizadas por poblaciones chichimecas, quienes eran cazadores-recolectores seminómadas que vivían en los territorios septentrionales, más allá del río Lerma. Basalenque $(1985,117)$ cuenta que en 1541 el primer virrey de Nueva Espańa, Antonio de Mendoza, cruzó la provincia, mientras acudía a Nueva Galicia para someter a los indios del Mixtón. En esta ocasión, y frente a los asaltos repetitivos, ordenó el establecimiento de una guarnición en Zinapécuaro con pretexto de proteger a los vecinos. Ciudad Real $(1976,159)$ precisa que estos ataques particularmente eran dirigidos hacia los religiosos: "Algunos religiosos han muerto, y casi todos han sido de nuestra orden". Desde entonces, la colocación de los soldados en Zinapécuaro estaba destinada, en prioridad, a la defensa de los misionarios. $\mathrm{Si}$ los tormentos que sufrieron las poblaciones de Zinapécuaro implicaron una protección militar, con certeza otro tanto sucedió en Acámbaro, ubicado más cerca de los territorios chichimecas, y por 
consiguiente, zona más expuesta. Esta situación tuvo repercusiones sobre la arquitectura de los conventos que alojaban a los frailes, y no en la de los templos donde sólo se hacían los oficios. Además, la construcción en piedra de los conventos ofrecía una protección más segura. Como lo señala P. Rojas $(1967,32)$, los monumentos de piedra fijan un carácter defensivo. La presencia de la torre-campanario de Acámbaro o de las almenas que coronan el techo del convento de Zinapécuaro son otros tantos elementos que participaron en la defensa del lugar de culto y de sus inquilinos. Estas características defensivas no se mencionan para el convento de Ucareo. Su ubicación en la sierra, más alejado del territorio chichimeca y de acceso difícil, lo preservó de las incursiones.

Es difícil hacer comparaciones con otras zonas septentrionales del territorio controlado por los españoles que sufren una situación político-militar similar, ya que la mayoría de las representaciones de lugares de culto en el norte de Nueva Espańa y en Nueva Galicia son estereotipadas. En particular es el caso de las iglesias figuradas en la conocida pintura de San Miguel y de San Felipe (Acuña 1987) y en la pintura del Nuevo Reino de Galicia (Acuña 1988). Aunque de estilo distinto, en estos dos mapas las iglesias toman los rasgos de casas estándares con una cruz encima. Sólo la pintura de Yuririapundaro, que también acompaña la Relación geográfica de Salaya y Acámbaro, presenta un edificio conventual con características arquitectónicas reconocibles (Acuña 1987). Este convento franciscano se compone de una iglesia y un campanario, figurados con pequeños rectangulares que materializan piedras en escuadra, y a su lado una estructura con pórtico, un segundo piso y un techo plano no presenta indicios sobre los materiales de construcción empleados. La similitud de las estructuras y de los materiales de construcción identificados en los conventos de Acámbaro y de Yuriripundaro, con certeza se debe a una situación político-militar compartida, en particular, a su cercanía con los asentamientos chichimecas y a los asaltos que debían de sufrir los poblados. ${ }^{32}$

${ }^{32}$ Otros edificios religiosos igualmente fueron objeto de estudios profundos, en particular podemos mencionar el trabajo de Marie Thérèse Reau (1991) sobre las portadas franciscanas en las regiones de Texcoco, Toluca, Tepalcingo y Sierra Gorda, pero esta úl- 


\section{ConClusión}

Aunque la difusión de los misionarios dentro del territorio durante el siglo Xvi parece responder a un cierto oportunismo y a una voluntad de difundir la fe cristiana rápidamente y al mayor número posible, este primer esbozo de estudio del sistema constructivo de los edificios religiosos pone de manifiesto una verdadera estrategia de asentamiento. La inversión proporcionada por los frailes en los edificios de culto es claramente proporcional a su rango en la pirámide eclesiástica. Se hace mayor hincapié en los conventos, que aparecen muy temprano como estructuras complejas. Además de su composición que agrupa todos los componentes para el mantenimiento y el desarrollo del núcleo eclesiástico, los conventos fueron concebidos para perdurar en el tiempo. Rápidamente, los materiales empleados atestiguan una voluntad de permanecer en el territorio. En este sentido, los conventos cristianos de la Nueva Espańa se inscriben dentro de la tradición europea. En cambio, las iglesias demuestran una inversión menor, que continúa hasta principios del siglo XVII. A pesar de su establecimiento en algunas ciudades importantes, los materiales empleados eran muy modestos. Sin embargo, la jerarquización de los edificios no fue la única causa de esta distinción de sistema constructivo. A la luz de esta documentación, aparece muy claramente que la elección de los tipos de materiales se debe a una influencia conjunta del estatus del edificio, del acceso a las materias primas y de la función paralela que juegan los edificios (la de ciudadela). Estos dos últimos criterios, muchas veces subestimados, probablemente, fueron el origen de las distinciones mayores entre los monumentos.

Este estudio preliminar pone de manifiesto el establecimiento del lugar de culto en el corazón de la vida rural. Sin embargo, una mejor comprensión de los sistemas constructivos primitivos sólo se podrá obtener a través de la adquisición de datos complementarios y, en particular, de la apertura de sondeos arqueológicos.

tima se enfoca principalmente en los aspectos arquitectónicos de fases de construcción posteriores (XVII y XVIII). 
BibliografíA

Acuña, René, ed. Relaciones Geográficas del siglo XVI: Michoacán. Etnohistoria, Serie antropología, 74. Mexico: IIA-UnAM, 1987.

. Relaciones Geográficas del siglo XVI: Nueva Galicia. Mexico: IIA- UNAM, 1988.

Alcalá, Jerónimo de. Relación de Michoacán. Zamora: El Colegio de Michoacán, 2008.

BASAlenque, Diego de. Los agustinos, aquellos misioneros hacendados. México: Secretaría de Educación Pública, 1985.

Beaumont, Pablo. Crónica de Michoacán, México. 3 vols. México: Publicaciones del AGn, Talleres Gráficos de la Nación, 1932.

Ciudad Real, Antonio de. Tratado curioso y docto de las grandezas de la Nueva España, relación breve y verdadera de algunas cosas de las muchas que sucedieron al padre fray Alonso Ponce en las provincias de la Nueva España siendo comisario general de aquellas partes. 2 vols. México: IIH-unAM, 1976.

DARRAs, Véronique. Etudes des sources thermales précolombiennes, incidences économiques et biochimiques d'un complexe hydrothermal sur les populations de Chupicuaro (Guanajuato, Mexique), Période préclassique récente (500 av.-J.C.-200 apr.-J.C.). París: Compte rendu d'activité scientifique, 2000.

Kubler, George. Arquitectura mexicana del siglo XVI. México: Fondo de Cultura Económica, 1983.

. "Ucareo and the escorial". Anales del Instituto de Investigaciones Estéticas de México 2(8) (1942).

LEFEBVRE, Karine. L'occupation du sol dans la région d'Acámbaro entre le Postclassique récent et le XVIe siècle. 2 vols. Tesis de Doctorado en Arqueología. Université de Paris I, Panthéon-Sorbonne, 2012.

Muriel, Josefina. Hospitales en la Nueva España (fundaciones en el siglo XVI). 2 tomos. México: UnAM, Cruz Roja Mexicana, 1990.

Paso y Troncoso, Francisco. "Suma de visitas de pueblos por orden alfabético, manuscrito 2,800 de la Biblioteca Nacional de Madrid, anónimo de la mitad del siglo Xvi". En Papeles de la Nueva España, segunda serie, geografia y estadistica. 2 tomos. Madrid: Est. Tipográfico "Sucesores de Rivadeneyra”, 1905. 
Réau Marie, Thérèse. Portadas franciscanas: La decoración exterior de las iglesias de México en el siglo XVIII: regiones de Texcoco, Toluca, Tepalcingo y Sierra Gorda. México: CEMCA, El Colegio Mexiquense, 1991.

Ricard, Robert. La conquista espiritual de México. México: Fondo de Cultura Económica, 1986.

Rodríguez Álvarez, María de los Ángeles. Usos y costumbres funerarias en la Nueva España. México: El Colegio de Michoacan y El Colegio Mexiquense, 2009.

Rojas, Pedro. Acámbaro colonial: estudio histórico, artístico e iconográfico. México: Impr. Universitaria, 1967.

Warren, J. Benedict. Vasco de Quiroga y sus hospitales pueblo de Santa Fe. Morelia: Ediciones de la Universidad Michoacana, Difusión Cultural, Editorial Universitaria, 1977. 